\title{
Giovanni Bassano's Divisions. A Computational Approach to Analyzing the Gap between Theory and Practice
}

\author{
Sarig Sela \\ Publication status: Published. Sarig Sela, “Giovanni Bassano’s Divisions. A \\ Computational Approach to Analyzing the Gap between Theory and Practice." Rivista di Analisi \\ e Teoria Musicale 25 no. 2 (2019): 33-55.
}




\begin{abstract}
"Division Ornamentation Practice" refers to the $16^{\text {th }}$-century phenomenon of embellishing a known melody in an extemporaneous or more pre-planned manner. 11 division instruction manuals were published by different performers during the $16^{\text {th }}$ century and the first two decades of the $17^{\text {th }}$ century. It is a common belief today that if performers wish to learn how to improvise divisions in a specific performer's style, they need to practice the performer's manual. In this paper, I challenge this assumption, demonstrating that, at least with the cornetist and composer Giovanni Bassano, there is an unsurmountable gap between his manual ornamentations, called here figurations, and the figurations he used in his division pieces. Surprisingly, in fact, Bassano uses less than $3 \%$ of his manual figurations in his division pieces. This raises the intriguing question of whether it is effective to practice Bassano's manual figurations in learning to improvise in his style. I proposed three computational models to examine this question. None of them yield an overlapping ratio that suggests close affinity between the manual figurations and the division figurations that Bassano used in his division pieces. Moreover, I show that Bassano's manual figurations are longer, faster and have a higher pitch range than the division figuration. Based on these findings, I recommend performers who wish to improvise in Bassano style to practice his figuration divisions rather than his manual figurations.
\end{abstract}




\section{Introduction}

Considerable evidence shows that $16^{\text {th }}$-century professional musicians needed not only to be able to perform music as written but also to ornament it, whether completely extemporaneously or partially pre-planned. The most common technique of ornamentation in this period is division, or diminution, in which the notes of a musical line or lines are divided into shorter notes according to the rules of musical composition. ${ }^{1}$ During the $16^{\text {th }}$ century and the first two decades of the $17^{\text {th }}$ century, 11 division instruction manuals were published by performers to help both professional and novice musicians acquire what I will call, in parallel with “performance practice," Division Ornamentation Practice (DOP). ${ }^{2}$

How to acquire DOP remains a burning question for modern performers who wish to revive this style of ornamentation, since the practice declined during the early Baroque period and had completely disappeared by the late Baroque. The available sources from 1535-1625 for reviving DOP are the instruction manuals just mentioned, other relevant treatises discussing $\mathrm{DOP}^{3}$ and division pieces written by performers. In addition, one can read the musicological research on this subject from the past 120 years. ${ }^{4}$

In contrast to the $16^{\text {th }}$-century students who could hear, imitate or directly learn from a master, modern musicians have no one to serve as a point of reference and therefore must revive

${ }^{1}$ Bass 2008; Bradshaw 1995; Brown 1976; Collins 2001; Dickey 2007; Haas 1931; Horsley 1951, 1961; Kuhn 1902; McGee 2003, 2008, 2012; Polk 2012; Smith 2011.

${ }^{2}$ The division instruction manuals from the $16^{\text {th }}$ century and the beginning of the $17^{\text {th }}$ century are Ganassi 1535; Ortiz 1553; Dalla Casa 1584; Bassano 1585; Rognoni 1592; Conforto 1593; Bovicelli 1594; Virgiliano ca. 1600; Brunelli 1610; Rognoni-Taeggio 1620; Spadi 1624.

${ }^{3}$ Coclico 1552; Bermudo 1555; Finck 1556; Zacconi 1592.

${ }^{4}$ See footnote 1. 
DOP from scratch. Although some authors of manuals state that it is sufficient for acquiring DOP, even professionally, to follow the instructions in the manuals and no additional guidance is necessary [McGee 2008], one must take into account that the manuals were intended for a $16^{\text {th }}$ century ear and not for a modern musician who has been exposed to the musical styles and aesthetics of the following centuries [Burstyn 1997]. Moreover, some of the promise of competent self-learning using the manual alone is probably a commercial exaggeration to increase the sales of the manuals.

The manuals provide many examples of figurations (see Figure 1) and descriptions of a well-defined mechanism for ornamenting a melodic interval by embedding such figurations. Nevertheless, musicologists have observed that the manuals lack musical context to help determine where and in what density to use the figurations in a musical piece [Brown 1976; McGee 2008]. Some of these issues are in fact discussed in the treatises. ${ }^{5}$

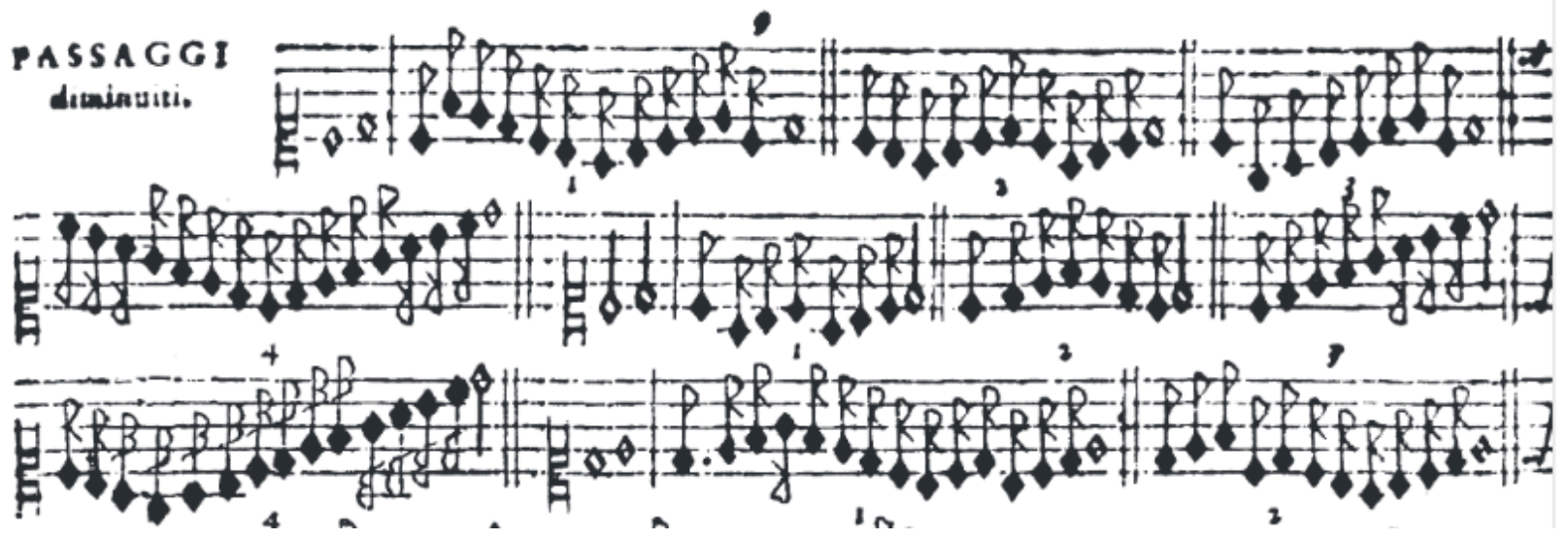

${ }^{5}$ See footnote 3 as well as Bridgman 1956 and Blackburn-Lowinsky 1993. 
Figure 1. Extract from Giovanni Bassano, Ricercate, passaggi et cadentie (1585). The melodic interval shown in each case (ascending major second) has several choices of figuration for its ornamentation.

The pieces written by performers have the advantage of showing practical contexts for the figurations. In order to examine the current consensus on how performers today may acquire DOP, I undertook a research project that combined the three types of available sources: division manuals, treatises, and division pieces by performers.

I started by looking at the treatises for instructions on how to apply manual figurations in a written composition or during improvisation. The treatises reveal a standard procedure for how to apply the manual figurations to a given melody, as I examine below. In most of the manuals, the figurations are organized by the interval they ornament. Each interval has several figurations that the performer can choose from, using the figuration vocabulary provided by the author of the manual. The performer is supposed to practice the figurations provided for each interval, then apply them while improvising or in the process of writing a division piece upon a known melody.

\section{The Bassano Corpus}

One particular famous performer-composer, Giovanni Bassano (ca.1560-1617), published both a large division manual containing extensive examples of figurations and also a second book containing numerous division pieces, so I chose him as a test case for my study. For a comparison between theory and practice, a large statistical sample size of both what I will call manual figurations and division figurations is necessary to produce meaningful results. Another reason for choosing Bassano is that he is considered by musicologists and performers to be a "classical" ornamentor [Dickey 2007,313] in the sense that he does not overuse ornamentation, 
and both his division pieces and the figurations themselves are not excessively fast or virtuosic in comparison with those of ornamentors such as Girolamo Dalla Casa and Riccardo Rognoni [Carter 1989; Dalla Casa 1584; Rognoni 1592, 1594]. Moreover, Bassano has been recommended by a leading modern performer, the cornettist Bruce Dickey, as a starting point for learning DOP [Dickey 2007, 313].

For my analysis I created a corpus consisting of all of Bassano's division pieces. In his Motetti, madrigali et canzoni francese (1591) there are 37 Soprano divisions and seven Bass divisions. I omitted the six viola bastarda divisions - a special form of division in which the figurations are based on more than one voice of the original piece, thus "bastardized". From his publication Ricercate, passaggi et cadentie (1585), I included 2 more Soprano divisions, which he devised for Cipriano de Rore's madrigal Signor mio caro. The manual figurations - no fewer than 266 of them - were also taken from his Ricercate.

Motetti, madrigali et canzoni francese was published in Venice in 1591, but the only surviving exemplar was lost in World War II. Fortunately, a $19^{\text {th }}$-century manuscript copy is held by the Staats-und Universitätsbibliothek Hamburg. The copy was discovered by Ernst Ferand (1961), who believed it to have been copied by the German musicologist Friedrich Chrysander (1826-1901) in 1890. Ferand found additional copies of division manuals made by Chrysander [Bassano 1585; Bovicelli 1593; Rognoni 1592] and reported that the copies were accurate and reliable.

It is important to understand that Bassano's ornamentations are not only instrumental. Although he was himself an instrumentalist and not a singer, he specifies in his first sentence, "to the reader", of his Ricercate, passaggi et cadentie [Bassano 1585] that the divisions are to be performed either by singers or by instrumentalists: 
Desirous, as much as I am able, to be of benefit to all excellent

musicians who delight in making diminutions, either by the simple voice or

with instruments - either by one or the other means - I wanted to share this my

work with you. ${ }^{6}$

\section{Preparing the Sets for Comparison}

To extract figurations from the division pieces I followed Sylvestro Ganassi’s basic definition of the boundaries of figuration: "first, you must remember that every division [figuration] must begin and end with the same note as the unornamented ground." [Ganassi 1535, ch. 13]. Figure 2 shows how I compared one of Bassano's division pieces with its unornamented ground (the Soprano voice of Rore's madrigal Ancor che col partire in this example) and extracted three figurations

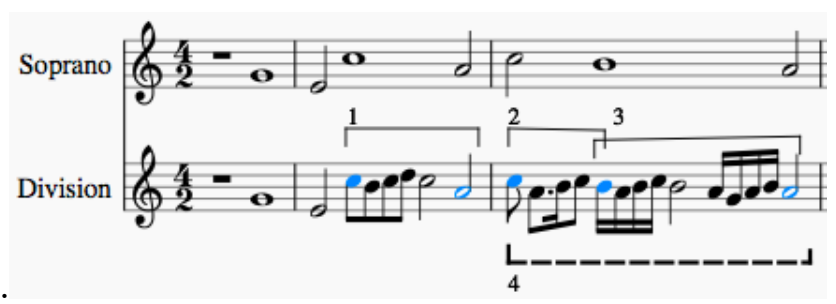

Figure 2. Extraction of three figurations from Bassano's division upon Rore's madrigal Ancor che col partire.

Figurations 2 and 3 overlap: the last note of figuration 2 is the first note of figuration 3 (note B). Let us define the term chained figuration as such an overlapping sequence of figurations (here marked as figuration 4), reserving simple figuration for figurations that are not

\footnotetext{
${ }^{6}$ Original text: "Desideroso, per quanto io posso, di giovare alli virtuosi Musici, quali ò con la semplice voce, ò con istrumenti, ò con l'uno, ò l'altro modo si dilettano diminuire, Hò voluto far loro parte di queste mie fatiche" (Bassano, 1585).
} 
chained. Applying Ganassi's definition to Bassano's division pieces yields 2,402 instances of simple figuration.

Most manuals mention that all figurations may be manipulated by two different "operations", as they are called in computational models:

(1) transposing them diatonically [e.g. Ganassi 1535, ch. 6], or in other words keeping the diatonic melodic-interval sequence of the figuration, and

(2) by altering their rhythm: usually halving or doubling the entire figuration and sometimes altering the proportions of the internal duration (see Figure 3). I took these operations on figurations into the model that I developed, defining that two figurations are of the same type, or in other words are equivalent, if it is possible to generate one from the other by diatonic transposition and/or by rhythmic alteration [Ganassi 1535, ch. 17]. Calculating the figuration types in the division pieces using these equivalence definitions reduces the original 2,402 figurations to 755 types of simple figuration.

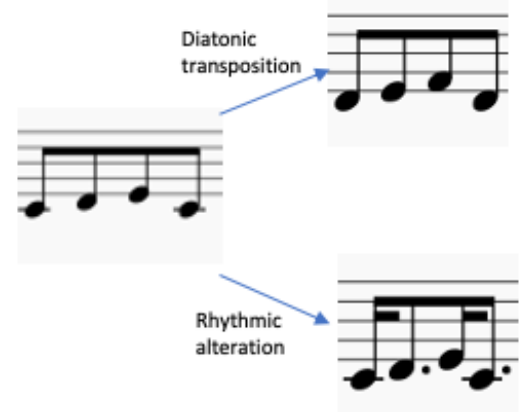

Figure 3. Example of a "fitter" function that can generate other instances of figuration out of one figuration type.

Bassano's manual contains a total of 266 figurations (104 of them being chained figurations and 42 cadences). 


\section{Ortiz's Exact-Matching Model}

Bassano himself did not write about how to use his manual in practice. Nevertheless, most manuals describe a particular process, as indicated by Brown and others [Brown 2002].

Ortiz, 32 years before Bassano's publication, provides us with a clear description of this process:

One must take the voice that is to be varied and write it out again.

When he arrives at the place he wishes to vary, he should go to the [i.e. this]

book and search for that formation of notes; if it is a cadence, in the cadences, and if not, in the other notes, and in that part he should look at all the

figurations written [in the book] about those progressions, and select the one

[figuration] that he deems best and put it in place of the plain notes. In all the places he wishes to vary, he may do in like manner. ${ }^{7}$

Taken literally, Ortiz's description fits a process of composing better than improvising, as obviously one cannot look up a suitable substitute figuration in the manual while playing.

Along the lines proposed by Ortiz, I began by hypothesizing a straightforward "naïve" computational model to support a scenario for improvisation:

(1) At the stage of learning figuration, the performer's memory stores unbroken whole figurations that are indexed (classified) by their boundary interval.

(2) In performance, the performer recalls a candidate set of figurations from memory.

${ }^{7}$ Original text: "Hassi adonch' da pigliare quella voce che si vuol glossare \& andarla scriuendo di nuovo $\&$ arriuato dove vuol glosare, alhora sicorra al libro \& ritroui quella maniera de punti, si e cadenza in le cadenze ouero altri punti \& in quel loco ha da mirar tutte le differentie che stanno scritte sopre tali punti \& pigli quella che meglio gli pare ponendola nel loco de li punti piani \& in tutte quelle parte che vorra glosar facci di questa maniera" (Ortiz 1553, 6). 
(3) At this point an evaluation function helps the performer to choose the most suitable figuration from the candidate set for the musical context.

(4) Immediately afterwards a fitter function transposes and rhythmically manipulates the figuration to fit the musical context (as in Fig. 3).

\section{Model Evaluation}

Having both the manual figurations and the division figurations allows us to test the overlap ratio between the two sets of figurations. If the ratio is high, then we would consider Ortiz's exact-matching model to be possibly valid. Otherwise, we have to look for another model to explain the relation between theory and practice.

Relevant criteria for comparing the two sets of figurations should take into account the process I have just proposed. According to the process, figuration types are not supposed to be altered in any way - other than by transposition and rhythmic change - to fit the musical context. These types act as unchanged building-blocks that are supposedly taken directly from the manual. Therefore, to compare equality between two figurations, exact matching is more suitable than approximate matching.

Out of the 266 manual figuration types, I found only 20 division figuration types, or $2.65 \%$ of the figurations used in the division pieces $(20 * 100 / 755=2.65)$ (see Figure 4$)$. This result includes searching in the division pieces for chained figurations from the manual.

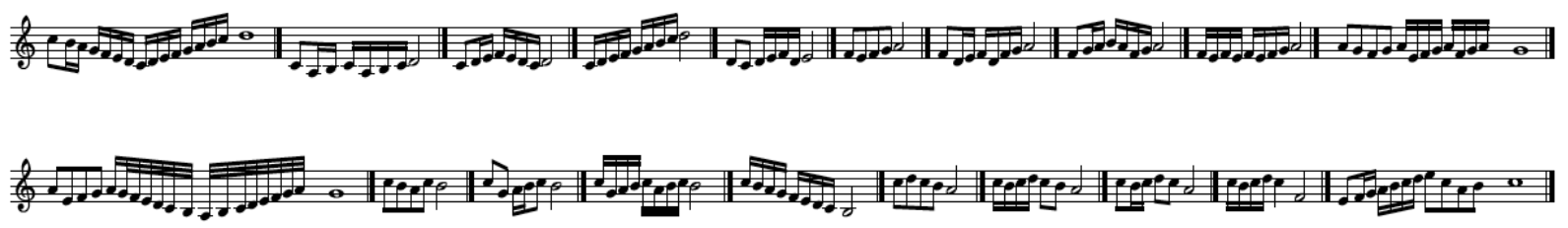


Figure 4. The 20 figuration types from the manual that are used in the division pieces.

This result is in total contradiction to Ortiz's model: Bassano used less than 3\% of his manual figurations in his division pieces.

A possible explanation of this discrepancy might be that Bassano changed his figuration vocabulary between the manual publication and the division pieces, which were published six years later. We can immediately show that this argument is poor, because Bassano provided two examples of division pieces in his manual. If the argument about changed vocabulary is true then one would expect to find many of the 266 figurations from the manual in its examples, yet only one figuration is actually found: the cadential figuration marked in brackets in Figure 5. Based on this evidence, Ortiz's exact-matching model does not apply to Bassano.

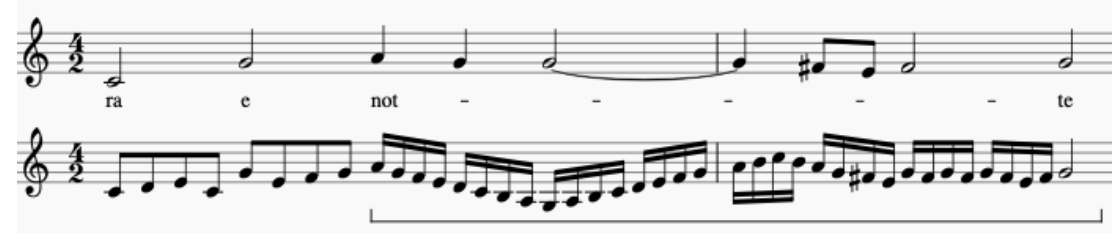

Figure 5. Rore's madrigal Signor mio caro as a division example in Bassano, Ricercate, passaggi et cadentie (1585).

Moreover, the evidence suggests that it may be ineffective to practice Bassano's manual for acquiring DOP.

But before concluding that the manual figurations are indeed ineffective for acquiring DOP, I wanted to test whether there could be a set of building blocks that were more basic than figurations. If that were the case, then extracting and practicing the building blocks would allow the performer to construct the division figurations better. If not, then I could conclude that practicing the manual figurations is ineffective. 
It is clear that if we keep breaking a melodic sequence into fragments, we will end up with single melodic intervals. Nevertheless, it is hard to believe that the brain is capable during performance of building up a full figuration of a long sequence of intervals (a mean of 9.9 intervals, see Table 2 ) while maintaining Bassano’s style of figuration and fitting it to the melodic context of the piece. After all, all Western melodies are built from melodic intervals, but not all melodies fit into Bassano’s figuration style. Therefore, I assume that only longer sequences than single melodic intervals could be considered as building blocks.

\section{Virgiliano's Sub-Figuration Model}

The second model I developed was based on the fourth rule in Aurelio Virgiliano's Il dolcimelo (ca. 1600):

The original note must be sounded at the beginning, in the middle, and at the end of the measure, and if it is not convenient to return to the original note in the middle, then at least a consonance and never a dissonance (except for the upper fourth) must be sounded. ${ }^{8}$

Virgiliano then provides important insight into the anatomy of figuration by stating that any figuration is composed of two sub-figurations.

An example of such a figuration $A$ is shown in Figure 6. Sub-figuration $\alpha_{l}$ (first five notes) is a unison figuration, i.e., a figuration that ornaments a unison melodic interval. Subfiguration $\alpha_{2}$ (last five notes) ornaments the interval of a descending second.

\footnotetext{
${ }^{8}$ Original text: "La nota del soggetto vuole esser sempre toccata nel prixipio, nel mezzo, e nel fine della battuta. E quando nel mezzo non tornasse comodo, si deve almeno toccar vicino in luogo, che gli sia consonante, e non mai dissonante, eccetto nella quarta di sopra" (Virgiliano ca. 1600).
} 
In my new model, instead of comparing figurations, I compare sub-figurations. Statistically, we would expect to find a higher overlap ratio by using the sub-figuration model over the Ortiz's exact-matching model. For example, let us assume that in addition to figuration $A$, which is constructed from sub-figuration $\alpha_{1}$ and sub-figuration $\alpha_{2}$ (see Figure 6), I have figuration $B$, which is constructed from the same sub-figurations as $A$ is constructed but in the opposite order: $\alpha_{2}$ then $\alpha_{1}$. According to Ortiz's model, the overlap ratio between figurations $A$ and $B$ is 0 , as $A$ is different from $B$; but according to Virgiliano's sub-figuration model, the overlap ratio between the figurations is 1 , as they use the same sub-figurations.

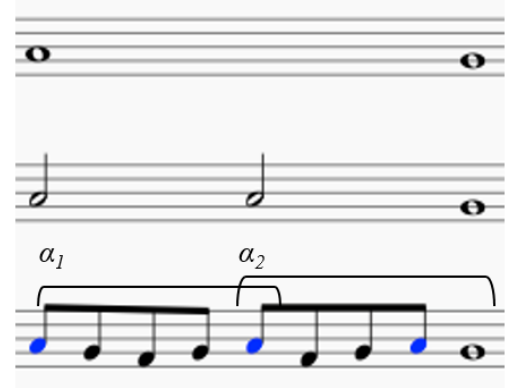

Figure 6. Virgiliano's anatomy of figuration A.

To consider this model in the Bassano context, I came up with three relevant questions:

(1) Do Bassano's figurations follow Virgiliano's fourth rule?

(2) Are Virgiliano's sub-figurations defined optimally for the process of reconstructing Bassano's figurations? Let us elaborate. By being able to reconstruct Bassano's division figurations from his manual sub-figurations, we strengthen the assumption that it is feasible for the brain to imitate the reconstruction process, and therefore practicing the manual figurations might be effective. Since it is statistically clear that smaller sequences of figurations have a better chance of overlapping than longer sequences have, the question is what the optimal cutting point of figurations into sub-figurations would be. It is not mathematically trivial to assume that cutting them in the middle will enable the reconstruction process to have the highest overlapping 
ratio. By proving that, out of all the possible cutting points, the middle point provides the highest overlapping ratio, as Virgiliano suggests, I strengthen his claim that the underlying building blocks of the figurations are the sub-figurations produced by the middle cutting point.

(3) By how much does the overlap ratio increase as a result of the new model?

The corresponding cognitive model may be described as follows:

(1) At the stage of learning figurations, the figurations are broken in the middle into two sub-figurations and stored separately in the memory.

(2) Just before applying a figuration to a given interval, both sub-figurations are recalled from the memory by a nondeterministic algorithm ("nondeterministic" because not all the factors are known), which possibly generates a completely new figuration type from them.

\section{Model Evaluation}

First, I examined Bassano's figurations to evaluate the extent to which they follow Virgiliano's fourth rule. Figure 7 shows Basssano's most frequent division figurations that do follow the rule. 

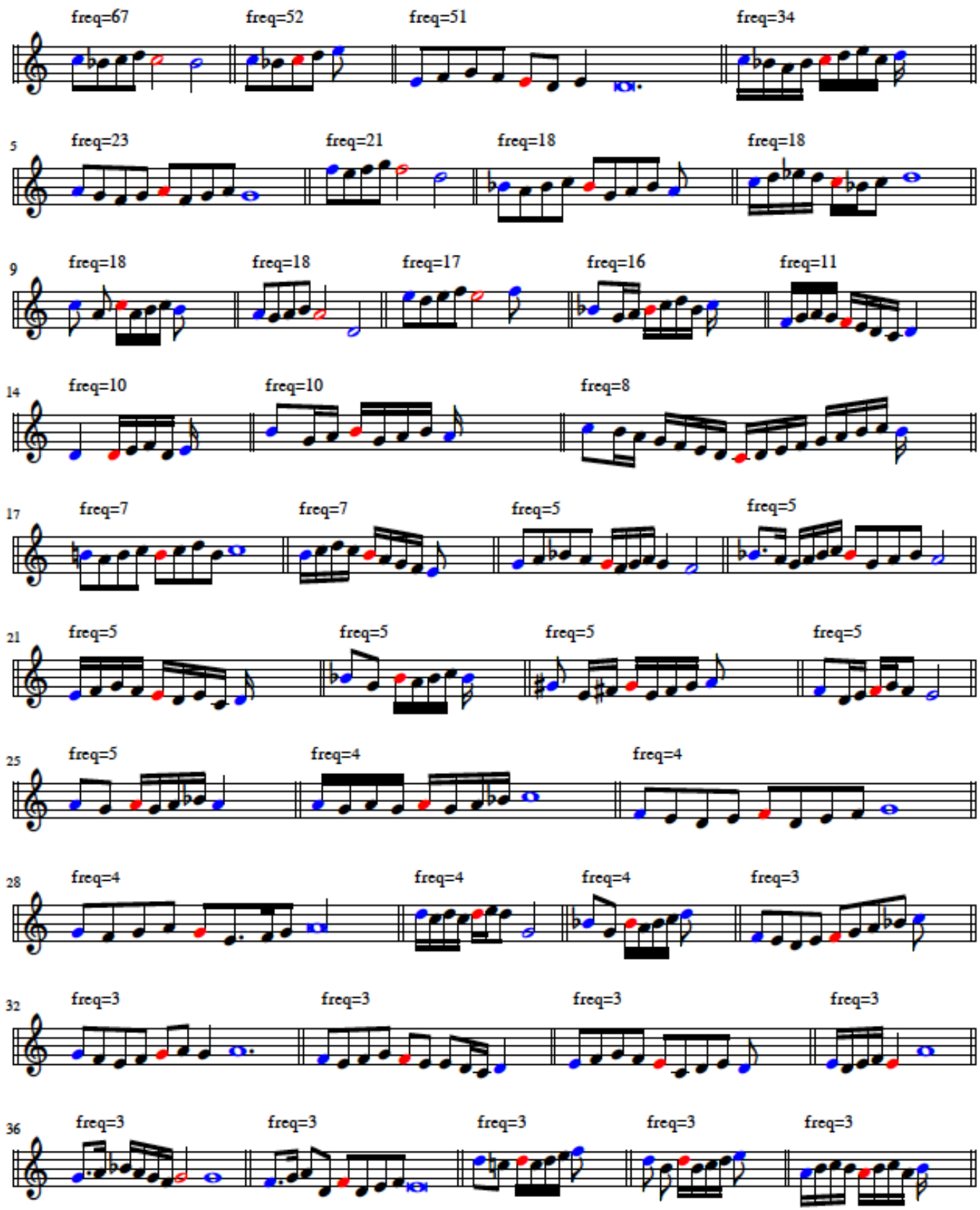

Figure 7. The 40 most frequent division figurations that follow Virgiliano's fourth rule, extracted from Bassano's division pieces.

In Table 1, I show the results for both the manual and division figurations. As suggested by Virgiliano, there is a weaker version of the rule (row 2) where the middle note of figuration is not equal to the first figuration note but a consonance to the other voices of the composition. 
Row 3 in Table 1 shows that $75 \%$ of the figurations of the manual and $50 \%$ of the figurations of the divisions have a bipartite structure where the first part is a unison figuration. The first part can be perceived as a first-note ornamentation rather than an interval ornamentation, and the second part of the figuration has the responsibility to bridge the melodic interval of the original interval of the melody.

\begin{tabular}{|c|c|c|c|}
\hline & Feature & $\begin{array}{l}\text { Manual } \\
\text { figuration }\end{array}$ & $\begin{array}{l}\text { Division } \\
\text { figuration }\end{array}$ \\
\hline 1 & $\begin{array}{l}\text { Strongly enforced: first, middle and penultimate note pitches are } \\
\text { equal }\end{array}$ & $45 \%$ & $31 \%$ \\
\hline 2 & $\begin{array}{l}\text { Weakly enforced: first and penultimate note pitches are equal } \\
\text { and middle note is a consonance }\end{array}$ & $\mathrm{N} / \mathrm{A}^{9}$ & $48 \%$ \\
\hline 3 & $\begin{array}{l}\text { Unison bipartite structure: Figuration's first and middle note } \\
\text { pitches are equal }\end{array}$ & $75 \%$ & $50 \%$ \\
\hline
\end{tabular}

Table 1. Adherence to Virgiliano's fourth rule in Bassano's manual and division figurations.

Although Virgiliano states that the cutoff point for sub-figurations is the middle of the figuration, theoretically, there could be a better cutoff point to create the smallest possible set of sub-figurations. To find the optimum point, I broke all the figurations into sub-figurations each time at different deviation offsets from the middle point of the figuration and checked the size of the sub-figuration sets for each deviation value. The deviation offset from the middle point in this test is based on the following semiminim (crotchet) note values in each iteration: $[-2,-1.5,-$ $1,-0.5,0,0.5,1,1.5,2]$. For example, if the middle point of a figuration is 2 semiminims from the beginning of the figuration, then a -0.5 offset means that I break the figuration at $2-0.5=$ 1.5 semiminims from the beginning.

\footnotetext{
${ }^{9}$ N/A because the manual does not supply the context of the other voices, therefore I cannot verify that there is a consonance.
} 


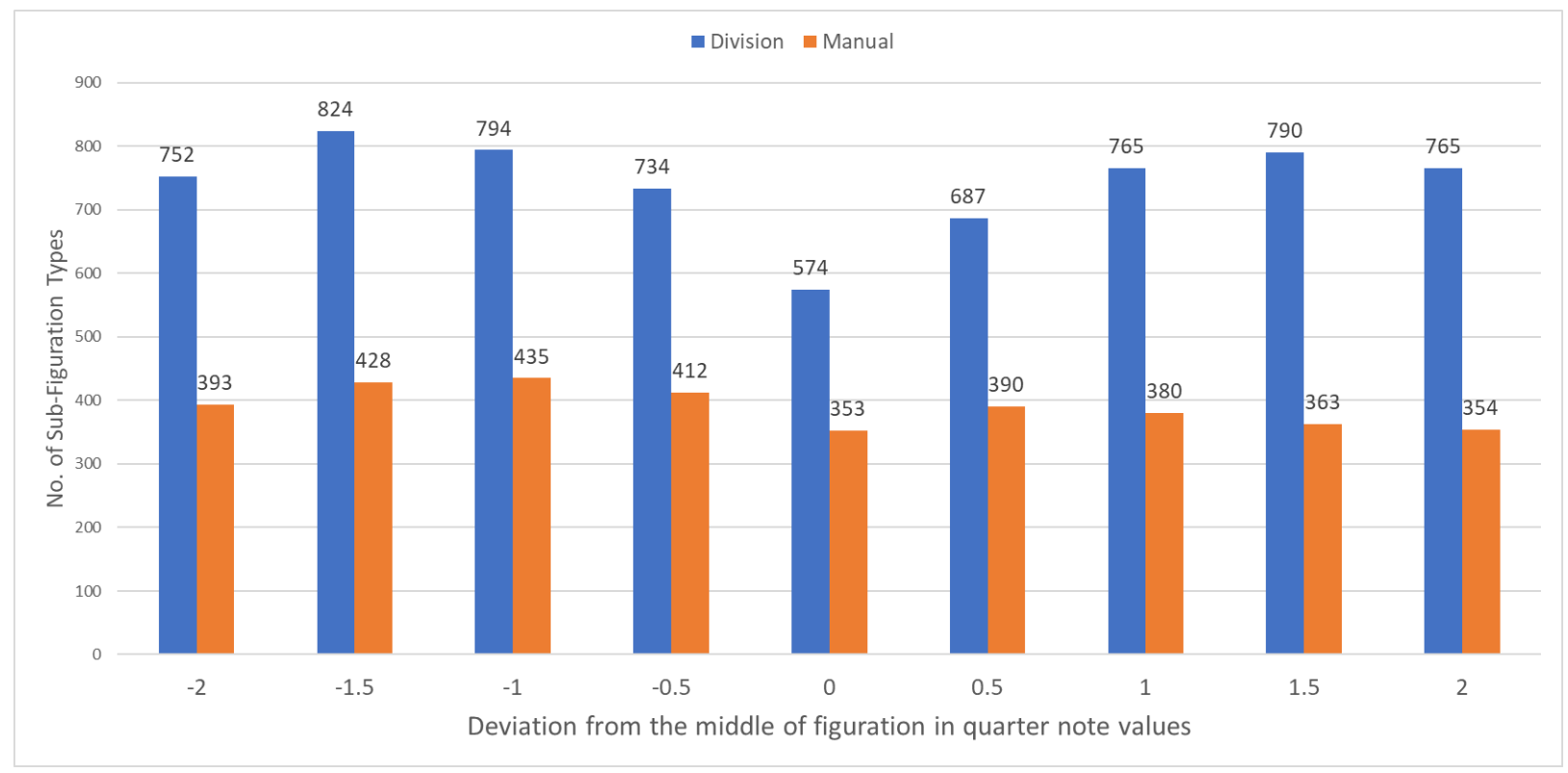

Figure 8. The optimal place to cut off figurations into sub-figurations is at the middle, as it generates the minimum number of sub-figuration types.

Figure 8 shows that the smallest size of sub-figuration set occurs when the cutoff point of the figurations is exactly in the middle, for both the division and the manual figurations. Or in other words, the minimum number of sub-figuration types is derived from the figurations if they are cut in the middle, as Virgiliano suggested.

My results showed that the overlap ratio between the manual and division figuration types increased from $2.65 \%$ to $20.56 \%$ when the new sub-figuration sets were used instead of the original figurations. This led to the conclusion that Virgiliano's sub-figuration model better explains Bassano's process of applying manual figurations in a division piece. It is important to note that such a model has two main advantages: (1) If one practices the division figurations, then the number of items to memorize decreases from 755 (see Preparing the Sets for Comparison above) to 574 (see the column block at $\mathrm{x}=0$ in Figure 8). This means that there are fewer items to store in the memory. On the other hand, if one practices the manual figurations, then the number of items to memorize increases from 266 (see Preparing the Sets for 
Comparison) to 353 (again see Figure 8 at $\mathrm{x}=0$ ). This suggests that the sub-figuration model requires more items to memorize for the manual figurations, but (2) each item is shorter and therefore easier to memorize.

Although this model provides a "safe" way to generate and apply figurations without violating any compositional rules, it still lacks the crucial level of freedom observed in Bassano's division pieces. Therefore, I added a certain degree of freedom of manipulation in my next model to expand the number of figurations that can be derived from the manual figurations, or the domain of choices.

\section{Approximate-Matching Model}

Approximate matching is based on the ability to define a measure of similarity between figurations. The approach is based on the cognitive assumption that, while executing a piece, a performer is capable of retrieving a stored figuration from memory and slightly manipulating it before applying it in a timely manner. The manipulation is not computationally trivial, as it must adhere to the syntactic rules of building a figuration. Although these syntactic rules are similar to the standard melodic rules of the sixteenth century, I discovered, for example, that the unison interval is never used within a figuration in Bassano corpus, although it is used quite frequently in melodies of the period.

Currently there is no single robust similarity measure for music, as such a measure must depend on the musical style, the experimental task and the background of the listener [Cambouropoulos-Crawford-Iliopoulos 2001; Grachten-Arcos-López De Mántaras 2004; Müllensiefen-Frieler 2004]. I chose the Levenshtein distance (LD) as my similarity measure, as it is commonly used in melodic-pattern recognition [Levenshtein 1966]. Similarity and distance are inversely proportional: as the similarity increases, the distance decreases, and vice versa. The 
LD between two words is defined as the minimum number of single-character edits (insertions, deletions or substitutions) required to change one word into the other.

To use this measure, I represented figurations as a sequence of diatonic intervals, just as I did in all previous tests. Each interval was mapped to a letter, so every figuration could be represented as a sequence of letters that I call a "word". Therefore, I defined the distance between two figurations as the LD between the words of the two figurations. LD does not take into account the length of the words, only the minimal number of edit operations. For example, the LD between the words "recorder" and "reorder" is 1, and the LD between "supercalifragilisticexpialidocious" and "qupercalifragilisticexpialidocious" is also 1; but clearly because the latter example uses more letters, the two words in it are more similar than those in the first example. To take that into account, I used the normalized LD measure. 10 "Normalized" in this context refers to rescaling the LD measure relative to the length of the words.

\section{Model Evaluation}

I built a distance matrix, $M$, containing the normalized LD between the division figurations and the manual figurations. Each row number in M corresponds to a manual figuration ID and each column in M corresponds to a division figuration ID. For example, row 4 of $\mathrm{M}$ represents a manual figuration with $\mathrm{ID}=4$ and column 5 of $\mathrm{M}$ represents a division figuration with $\mathrm{ID}=5$. The value at row 4 and column $5(\mathrm{M}[4,5])$ specifies the normalized $\mathrm{LD}$ between the manual figuration ID $=4$ and the division figuration ID $=5$. Figure 9 is an example of how to calculate the normalized LD between a manual figuration $i$ and a division figuration $j$.

${ }^{10}$ Formally, a normalized LD (NLD) can be expressed as: $\operatorname{NLD}=\operatorname{LD}\left(\mathrm{s}_{1}, \mathrm{~s}_{2}\right) / \operatorname{Max}\left(\left|\mathrm{s}_{1}\right|,\left|\mathrm{s}_{2}\right|\right)$, where $|\mathbf{s}|$ denotes the length of string $\mathrm{s}$. The similarity (S) measure can be expressed as: $\mathrm{S}=1-\mathrm{NLD}$. For more details see Müllensiefen-Klaus 2003. 
Each figuration consists of a sequence of 15 melodic intervals (the minus sign represents the down direction of the melodic interval). To generate the division figuration out of the manual figuration the 3 intervals in red need to be replaced (i.e., $\mathrm{LD}=3$ ). Therefore, the normalized Levenshtein Distance between the figurations is $3 / 15=0.2$. Therefore, the distance-matrix value for these two figurations at row $i$ and column $j$ is 0.2 (i.e. $\mathrm{M}[\mathrm{i}, \mathrm{j}]=0.2$ ). A short excerpt from such a matrix is shown in Figure 10.

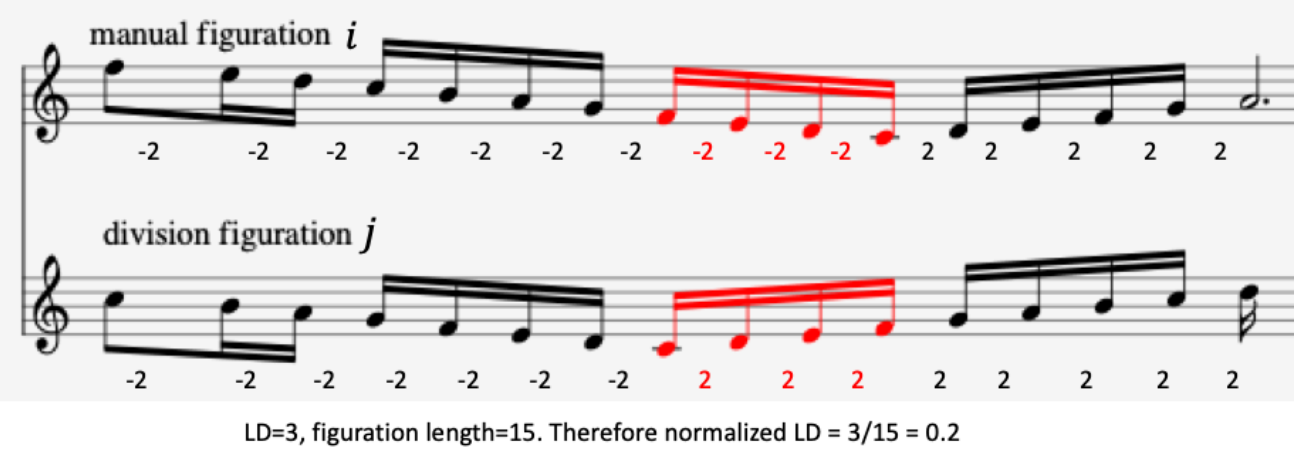

Figure 9. An example of how to calculate the normalized Levenshtein Distance (LD).

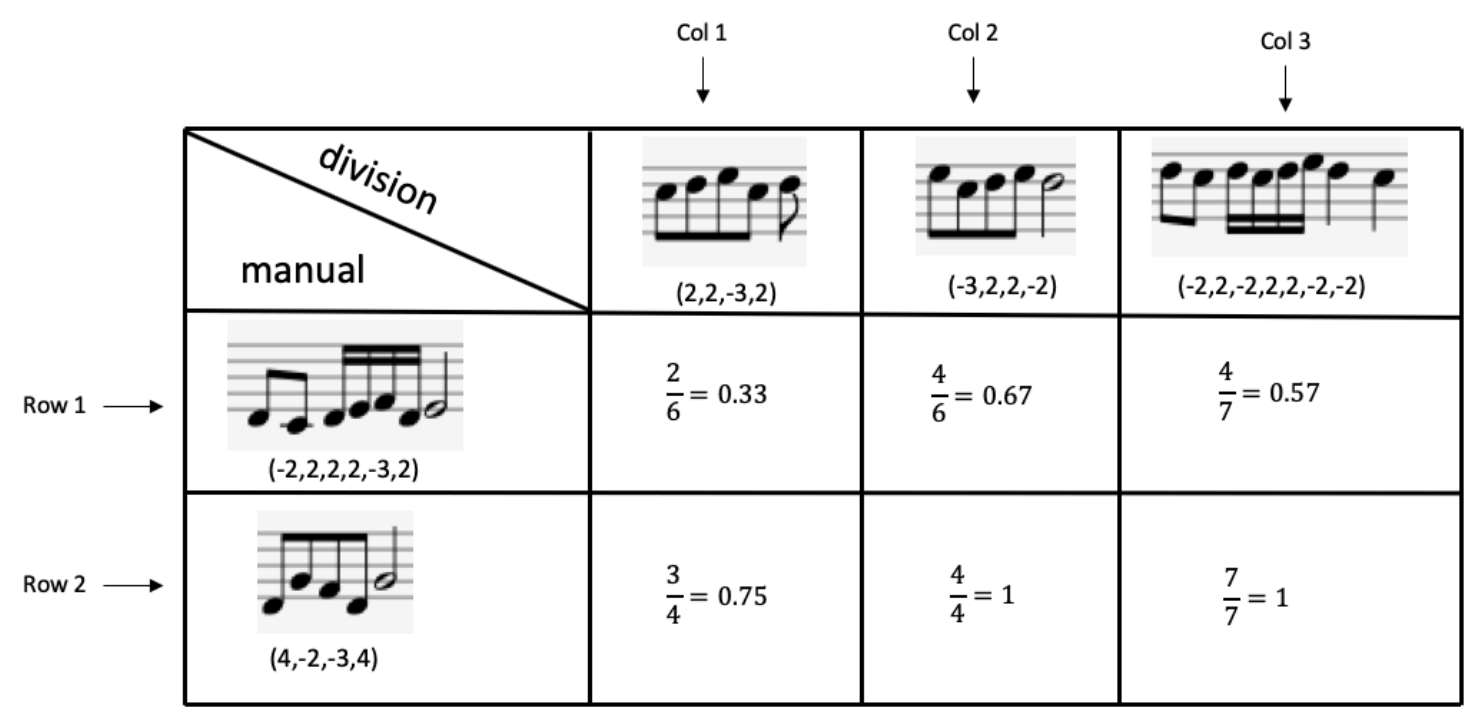

Figure 10. An example of how a normalized distance matrix $M$ is calculated. $M[1,1]=0.33$ because 2 operations are needed to transform the intervals of the manual figuration in row 1 into those 
of the division figuration in column 1, and the longest figuration of the two is of length 6 (therefore the normalized $L D=2 / 3=0.33$ )

The question for such a model is: what normalized LD can we accept as "similar enough" to be regarded as an overlap between figurations? Let us assume, for the sake of argument, that the brain's processing speed is one edit operation per second. Taking a tempo of one second per minim that is ornamented by a figuration of four intervals (each figuration note is a fusa, or quaver) yields one edit operation per four intervals, i.e., normalized $\mathrm{LD}=0.25$.

I found that there are 181 figurations at normalized $L D=0.25$. This means that applying one edit operation for every four interval sequences in manual figurations can generate 181 division figurations. Since there are 755 division figuration types, the overlap ratio is: $181 * 100 / 755=23.97 \%$ (the column block at $\mathrm{x}=0.25$ in Figure 11). For $\mathrm{x}=<0.25$ the overlap ratio is $50.73 \%$ figurations (the cumulative line). This means that if the brain is capable of manipulating one interval for every four sequential intervals, then $50.73 \%$ of the division figurations can be generated from the set of manual figurations. 


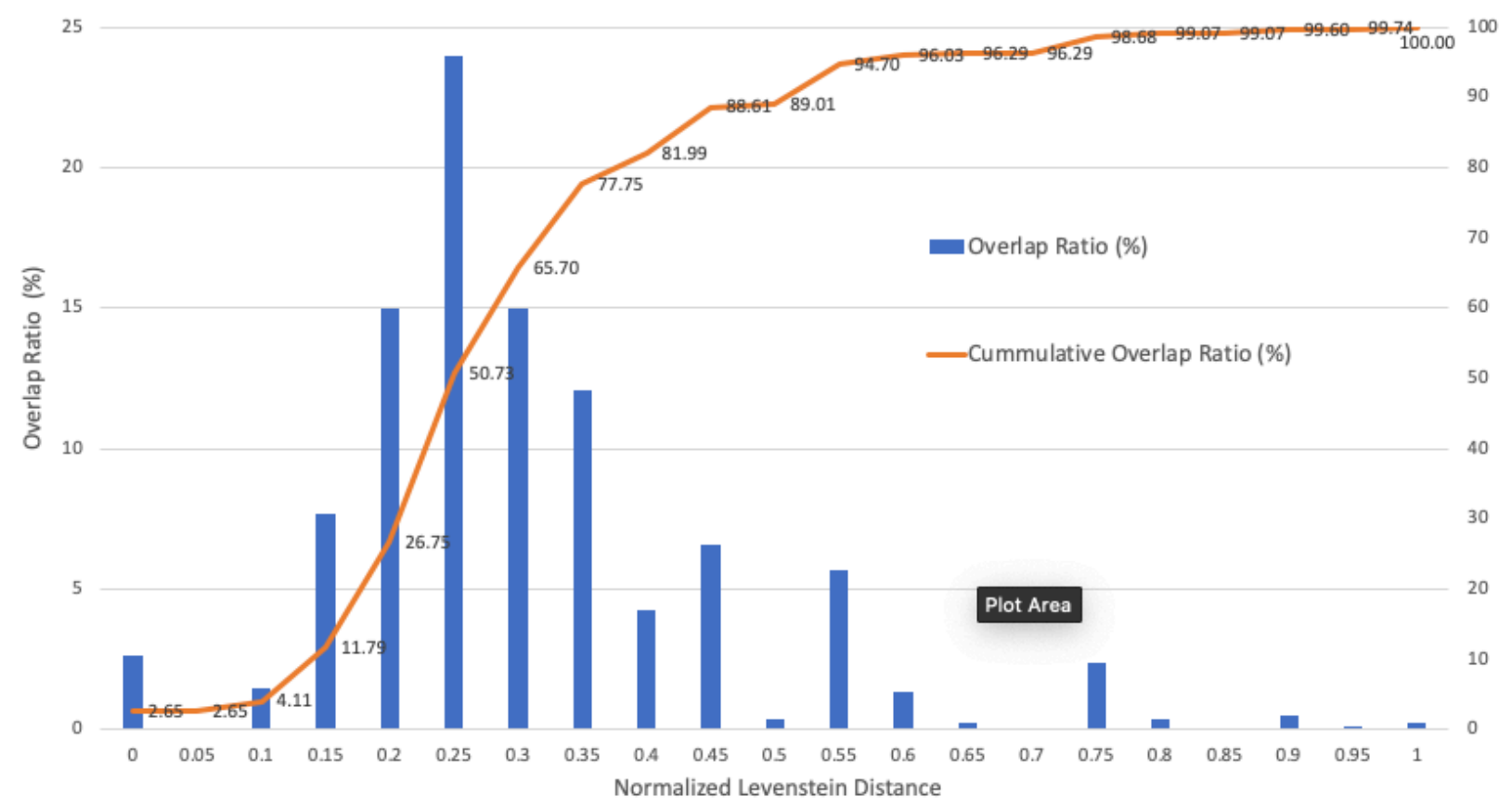

Figure 11. The overlap ratio at normalized LD between Bassano's division and manual figurations.

In sum, I started from a rigid model of exact matching as described by Ortiz, which yields an overlap ratio of $2.65 \%$. Moving to a model based on Virgiliano's fourth rule, I constructed a sub-figuration model, which raised the overlap ratio to $20.56 \%$. Finally, by allowing more flexibility to the manipulation process I obtained the much higher ratio of $50.73 \%$.

\section{Figuration Attribute Test}

I next constructed a test to answer the question of whether there are some intrinsic differences in attributes between the two figuration sets that would prevent the manual set being applied in the division pieces. For example, figurations with a large number of intervals in a given time span might obscure the other voices or change the original atmosphere of the composition. Or if the manual figurations are originally intended to span a breve and in the 
division pieces most of the figurations are of a semibreve, then dividing the note durations of the figuration in half might cause the figuration to sound too fast or obscure the meaning of the original piece, therefore making the manual figurations a bad choice to use in practice.

Therefore, I tested the following attributes: (1) sequence length: the number of intervals that comprise a figuration; (2) duration: the duration of a figuration in semiminims; (3) pitch range: the interval between the lowest and highest pitch notes of the figuration.

$\begin{array}{lllllll}\text { Feature } & \text { Group } & \text { Mean } & \text { SD } & \text { Median } & \text { Mode } & \text { IQR } \\ \begin{array}{l}\text { Sequence length (number of } \\ \text { intervals) }\end{array} & \text { Division } & 9.9 & 6.2 & 8 & 8 & 6 \\ \text { Duration (semiminims) } & \text { Manual } & 12.6 & 6.2 & 12 & 8 & 8 \\ & \text { Division } & 3.7 & 1.9 & 4 & 4 & 2 \\ \text { Pitch range (tones) } & \text { Manual } & 3.8 & 1.6 & 4 & 4 & 3.5 \\ & \text { Division } & 5.4 & 2.0 & 5 & 5 & 2\end{array}$

Table 2. Differences in attributes between Bassano's division and manual figuration sets.

As Table 2 shows, the biggest difference between the sets is the length of the figurations $(12.6-9.9=2.7$ interval sequences $)$ : on average the manual figurations consist of more notes than the division figurations do. Since the average difference in duration of the figurations is negligible $(3.8-3.7=0.1$ of a semiminim $)$, I can infer that there are not only more notes, but also faster notes (semifusas) on average per figuration in the manual figurations than in the division figurations. The pitch range is also bigger on average in the manual figurations (6.5$5.4=1.1$ diatonic seconds), which suggests more virtuosic and showy figurations.

These results demonstrate that Bassano's divisions are simpler and less virtuosic than his manual figurations. This difference might be due to the sixteenth-century criticism of excessive 
showy figurations that obscure the intention of the original melody's composer [Brown 1976; Collins 2001; McGee 2008].

\section{Summary and Conclusion}

I started my investigation about the relation between theory and practice by looking at the treatises for instructions on how to apply manual figurations in a written composition or during improvisation. The treatises describe a standard procedure for how to apply the manual figurations to a given melody. The manual figurations are organized by the interval they ornament, each interval having several figurations from which the performer can choose. The author of each manual has his own figuration vocabulary. The performer is supposed to practice the figurations provided for each interval and apply them while improvising or in the process of writing a division piece upon a known melody.

Since Giovanni Bassano provides both a large manual and numerous division pieces, I chose him as a test case for my study for how far the manual figurations were used in practice. Surprisingly, I found that Bassano uses less than 3\% of his manual figurations in his division pieces. This finding contradicts the procedure from the treatises. But before concluding that it is ineffective for modern performers who wish to improvise in Bassano style to practice the manual figurations, I wanted to see if I could find building blocks that worked better than figurations.

Virgiliano provides insight into the anatomy of figurations. In his fourth rule, he specifies that a figuration has a bipartite structure. The first half of the figuration is a sub-figuration which ornaments a unison interval, and the other sub-figuration ornaments the interval of the original figuration. This is exactly what I was looking for, as each sub-figuration is a smaller building block than a whole figuration and has a defined function. 
To consider Virgiliano's rule, I tested Bassano figurations and found that $48 \%$ of the division figurations and $45 \%$ of the manual figurations adhere to the rule. This provided us with the confidence that cutting figurations into sub-figurations is reasonable. My next test proved that the cutoff point in the middle is the most optimal for producing the minimum set of building blocks per set. The last stage of my test showed that by creating such sub-figurations from each set the overlap ratio between manual and division figurations was raised from $2.65 \%$ to $20.56 \%$.

The models I used do not take similarity between figurations into account: figurations are either equal or unequal in melodic interval sequences. But what if there are many figurations from the manuals that are unequal but still share the same melodic sequence for most of the sequence? To test that I needed to use a model that could measure the similarity between figurations: the approximate-matching model. I took a common similarity measure based on Levenshtein distance (LD), which measures the minimal number of edit operations needed to transform one figuration to another relative to the length of the figuration.

To be able to calculate the overlap ratio in the approximate-matching model I have to define the degree of similarity that I consider as "similar enough". Obviously, as I allow more edit operations to take place per figuration, more figurations are going to be considered as similar to each other and therefore the overlap ratio increases. Since the number of edit operations depends on the computational power of the brain (as the edit operations are done in real time), a threshold of the edit operations is needed to define the "similar enough" measure. I decided to take a threshold of 0.25 edit operations per interval. (The argument for that is elaborated in the model evaluation section of the approximate-matching model.) This means that I believe that the brain is capable of making one edit operation for every sequence of four intervals. At this threshold, the overlap ratio was raised to $50.73 \%$. 
In searching for an explanation of why Bassano himself did not utilize his own manual figurations in his transcriptions, I can postulate two possible ones: (1) The figurations are not meant to be used literally (copied) but to serve as a set of observations from which the performer should inductively extract formal rules to represent local patterns in the figurations. After this rule- $=$ induction process has been completed, the performer is expected be able to deductively generate new figurations by adhering to the inducted rules. (2) Bassano took the opportunity in the transcription publication to present a new set of figurations instead of redundantly repeating the manual figurations.

For the first explanation, although this process may be possible to some extent, I believe that in practice it has a low probability of occurring to occur in the $16^{\text {th }}$-century context. The manuals are usually presented as if they are foremost intended for amateurs. This is explicitly stated in the preface to most of the manuals. ${ }^{11}$ It is also implied by the fact that the manuals dedicate substantial parts to very basic information regarding music theory and playing, such as fingering charts for wind instruments. To be able to follow the inductive and deductive processes (as suggested by the explanation) requires an extremely high level of knowledge of music theory and quite an advanced scientific attitude. We do find one example of 10 rules formulated by Virgiliano ( $c a .1600)$ that try to help in generating figurations from scratch. Nevertheless, if this approach had been as useful as the explanation suggests, we would expect to find such rules in many publications, and this is not the case. On the contrary, we find many manuals with hundreds of figuration examples that proliferated during the 16th century. If it was easy for

${ }^{11}$ See, for example, Bassano (1585), "to the reader" section: “Although many other labors made by my betters on the subject of diminutions ought perhaps to restrain me from publishing my work, I did not want to deny beginners [emphasis added] this manner of discovered diminution practice, so that everyone may know how to use this practice." 
performers to deductively use these rules to generate figurations, why would they invest their money in buying manuals with hundreds of examples instead of buying a small booklet with a few sets of rules? Moreover, if it is so easy to inductively formulate rules for figurations, then why would manual authors, who were under economically competitive pressure, spend their energy in printing long manuals instead of cheaper short booklets with rules?

Moreover, Ortiz (as quoted in the Ortiz Exact-Matching Model section) explicitly specifies that the figurations should be taken from the manual as-is rather than being invented from scratch. The methodology of DOP is based on step-by-step instructions and therefore provides a pragmatic solution; The figurations are organized in the manual by the original interval they are supposed to embellish, so it will be easy for the performer to follow the instructions and find a figuration based on the interval the performer wants to ornament. This categorization of figurations in the manuals supports the step-by-step process. If the process of looking up figurations from the manual was for theoretical purposes only, then one could have categorized the figurations by other criteria, such as level of complexity or similarity, or by a higher semantic level (as suggested in Chapter 2). Therefore, the probability of the first explanation is low.

The second explanation for not using the manual figurations in the transcriptions on the basis that Bassano wanted to avoid redundancy and take the opportunity to present more figurations requires further testing of the two figuration sets. By revealing intrinsic differences between the manual and the transcription figurations, I strengthen the viewpoint that the transcription figurations are not just more examples of the same type as the manual figurations but possess distinctive attributes that fit practice better. Moreover, by showing these differences I disclose Bassano's aesthetic preferences related to practice that are not so evident in theory. 
For that purpose, I conducted the figuration-attribute test, which includes the figuration length (measured by the number of intervals comprising the figuration), duration (measured in semiminims) and pitch range (measured by the number of tones). The test shows that the manual figurations are longer and faster and have a higher range of pitch than the division figurations. This led me to conclude that the manual figurations are more virtuosic and showy than the division figurations, perhaps related to the $16^{\text {th }}$-century criticism of virtuoso performers who ornamented intensively to the point of interfering with the original message of the composition.

Even with the models I provided, I judged that the overlap ratio did not increase enough for the manual figurations to be considered effective. The alternative is obvious: to practice the division figurations instead of manual figurations. Moreover, by knowing the frequency of occurrence of each division figuration in the corpus, we can even have an indication of which figurations to use more frequently in order to achieve a better stylistic resemblance to Bassano's style.

In conclusion, the gap between theory and practice is too large to fill. Performers who wish to improvise in Bassano's style and adhere to his aesthetical preferences should practice more on his division figurations rather than his manual figurations. 


\section{References}

Bass, J. B. (2008). "Rhetoric and Musical Ornamentography: Tradition in Sixteenth-Century Improvisation.” PhD diss., Univ. of Memphis.

Bassano, G. (1585). Ricercate, passaggi et cadentie. Giacomo Vincenzi - Ricciardo Andimo, Venezia.

Bassano, G. (1591). Motetti, madrigali et canzone francese. Giacomo Vicenti, Venezia (lost).

Bermudo, J. (1555). El libro llamado Declaración de instrumentos musicales. Osuna.

Blackburn, B. - Lowinsky, E. (1993). "Luigi Zenobi and his Letter on the Perfect Musician." Studi musicali 20: 61-107.

Bovicelli, G. B. (1594). Regole, Passaggi di musica.... Venezia.

Bradshaw, M. C. (1995). “Giovanni Luca Conforti and Vocal Embellishment: From Formula to Artful Improvisation.” Performance Practice Review 8, no. 1: 5-27.

Bridgman, N. (1556). “Giovanni Camillo Maffei et sa lettre sur le chant.” Revue de musicologie 38: $3-34$.

Brown, H. M. (1976). Embellishing Sixteenth-Century Music. Oxford University Press, Oxford.

Brunelli, A. (1610). Regole et dichiarationi. Firenze.

Burstyn, S. (1997). “In Quest of the Period Ear.” Early Music 25, no. 4: 693-701.

Caccini, G. (1601). Nuove musiche e nuova maniera di scriverle. Firenze.

Cambouropoulos, E. - Crawford, T. - Iliopoulos, C. S. (2001). "Pattern Processing in Melodic Sequences: Challenges, Caveats and Prospects." Computers and the Humanities 35, no. 1: $9-21$. 
Carter, S. (1989). “Francesco Rognoni’s 'Selva de varii passaggi’ (1602): Fresh Details concerning Early Baroque Vocal Ornamentation.” Performance Practice Review 2, no. 1: $5-33$.

Coclico, A. P. (1552). Compendium musices. Nürnberg.

Collins, T. A. (2001). “'Reactions against the Virtuoso': Instrumental Ornamentation Practice and the Stile moderno." International Review of the Aesthetics and Sociology of Music 32, no. 2: $137--52$.

Conforti, G. L. (1593). Breve et facile maniera d'essercitarsi a far passaggi. Rome.

Dalla Casa, G. (1584). Il vero modo di diminuir. 2 vols. Angelo Gardano. Venezia.

Dickey, B. (2007). “Ornamentation in Sixteenth-Century Music.” In J. T. Kite-Powell (ed.). A Performer's Guide to Renaissance Music. Indiana University Press. Bloomington \& Indianapolis, 300-24.

Ferand, E. T. (1938). Improvisation in Nine Centuries of Western Music: An Anthology with a Historical Introduction. A. Volk, Zürich.

Ferand, E. T. (1961). “Communications: Concerning Giovanni Bassano.” Journal of the American Musicological Society 14, no. 1: 419.

Finck, H. (1556). Practica musica. Wittenberg.

Ganassi, S. (1535). Opera intitulata Fontegara. Venice. English translation by H. Peter - D. Swainson. Robert Lienau. Berlin-Lichterfelde, 1997.

Grachten, M. - Arcos, J. L. - López De Mántaras, R. (2004). “Melodic Similarity: Looking for a Good Abstraction Level.” In ISMIR 2004, 5th International Conference on Music Information Retrieval, Proceedings. Universitat Pompeu Fabra, Barcelona, 210-15.

Haas, R. M. (1931). Aufführungspraxis der Musik. Athenaion, Potsdam. 
Habrard, A. - Inesta, J. M. - Rizo, D. - Sebban, M. (2008). “Melody Recognition with Learned Edit Distances.” In Joint IAPR International Workshops on Statistical Techniques in Pattern Recognition (SSPR). Springer, Berlin \& Heidelberg, 86-96.

Horsley, I. (1951). "Improvised Embellishment in the Performance of Renaissance Polyphonic Music." Journal of the American Musicological Society 4, no. 1: 3-19.

Horsley, I. (1961). “The Solo Ricercar in Diminution Manuals: New Light on Early Wind and String Techniques." Acta Musicologica 33: 29-40.

Kuhn, M. (1902). Die Verzierungs-Kunst in der Gesangs-Musik des 16.-17. Jahrhunderts (15351650). Breitkopf \& Härtel, Leipzig.

Levenshtein, V. I. (1966, February). "Binary Codes Capable of Correcting Deletions, Insertions, and Reversals.” Soviet physics doklady 10, no. 8: 707-10.

McGee, T. J. (2008). "How One Learned to Ornament in Late Sixteenth-Century Italy." Performance Practice Review 13, no. 1: 1-16.

McGee, T. J. (2012). "Vocal Performance in the Renaissance." In C. Lawson - R. Stowell (ed.). The Cambridge History of Musical Performance. Cambridge University Press, Cambridge, 318-34.

McGee, T. J. (ed.) (2003). Improvisation in the Arts of the Middle Ages and Renaissance. Western Michigan Univ., Medieval Institute Publications.

Müllensiefen, D. - Frieler, K. (2003). “Cognitive Adequacy in the Measurement of Melodic Similarity: Algorithmic vs. Human Judgments.” Computing in Musicology 13: 147-76. Newell, A. (1994). Unified Theories of Cognition. Harvard University Press, Cambridge MA. Orpen, K. S. - Huron, D. (1992). "Measurement of Similarity in Music: A Quantitative Approach for Non-Parametric Representations." Computers in Music Research 4: 1-44. 
Ortiz, D. (1553). Tratado de glosas sobre clausulas y otros generos de puntos en la musica de violone. Rome. English translation by P. Farrell in Journal of the Viola da Gamba Society of America 4 (1967): 5-9.

Polk, K. (2012). "Instrumental Performance in the Renaissance.“ In C. Lawson - R. Stowell (ed.). The Cambridge History of Musical Performance. Cambridge University Press, Cambridge, 335-52.

Rognoni, R. (1592). Passaggi per potersi essercltare nel diminuire terminatamente. Venezia.

Rognoni, R. (1594). Il vero modo di diminuire. Venezia.

Rognoni-Taeggio, F. (1620). Selva di varii passaggi. Milano.

Rore, C. d. (1547). Anchor che col partire. in Madrigali a 4 voci, libro 1. Antonio Gardano, Venezia.

Smith, A. (2011). The Performance of 16th-Century Music: Learning from the Theorists. Oxford University Press, New York.

Spadi, G. B. (1624). Libro de passaggi ascendenti et descendenti. Venezia.

Virgiliano, A. (ca. 1600). Il dolcimelo (ms.).

Zacconi, L. (1592). Prattica di musica. Venezia. 


\section{Appendix}

As can be observed in Figure 12 there is no substantial difference between the relative frequency of the diatonic melodic intervals of the manual figurations and the division figurations. On the other hand, there are two main differences between the compositions' melody and the figurations' relative melodic interval frequencies: (1) the use of P1 (which is the unison interval) in the compositions vs. the almost total absence of it in the figurations; (2) the compositions' melody tends to have more descending stepwise motion than ascending stepwise motion, whereas figurations exhibit the opposite trait.

The first difference can be explained by the fact that acoustically performing a melodic unison is less distinct than performing any other melodic interval (two notes with a different pitch). The distinction becomes less observable as the tempo is faster. Therefore, since the figurations are on average are 4 times faster than the compositions' melodies (the division figurations are usually eighteenth notes whereas the composition melodies are half notes) the avoidance of unisons in the figurations is a probable explanation; Moreover, in the unison interval, the only separator between the notes is the articulation between the notes. In the original compositions the unisons are usually syllabic and therefore make the separation between the notes sound more natural than the melismatic nature of the intervals of the figurations.

The second difference can be explained as follows: for the compositions' melodies it is shown that there are more descending stepwise intervals than ascending stepwise intervals. The reason for that is related to the tendency for jumps in $16^{\text {th }}$-century melodies to be followed by stepwise motion in the opposite direction. This tendency is less restrictive if there are descending $4^{\text {ths }}$ or larger leaps. Therefore, there are fewer ascending stepwise intervals than descending stepwise intervals in the compositions' melodies. On the other hand, figurations have more 
descending leaps than ascending leaps, i.e., the tendency is more restrictive and therefore exhibits more ascending stepwise intervals than the compositions' melodies.

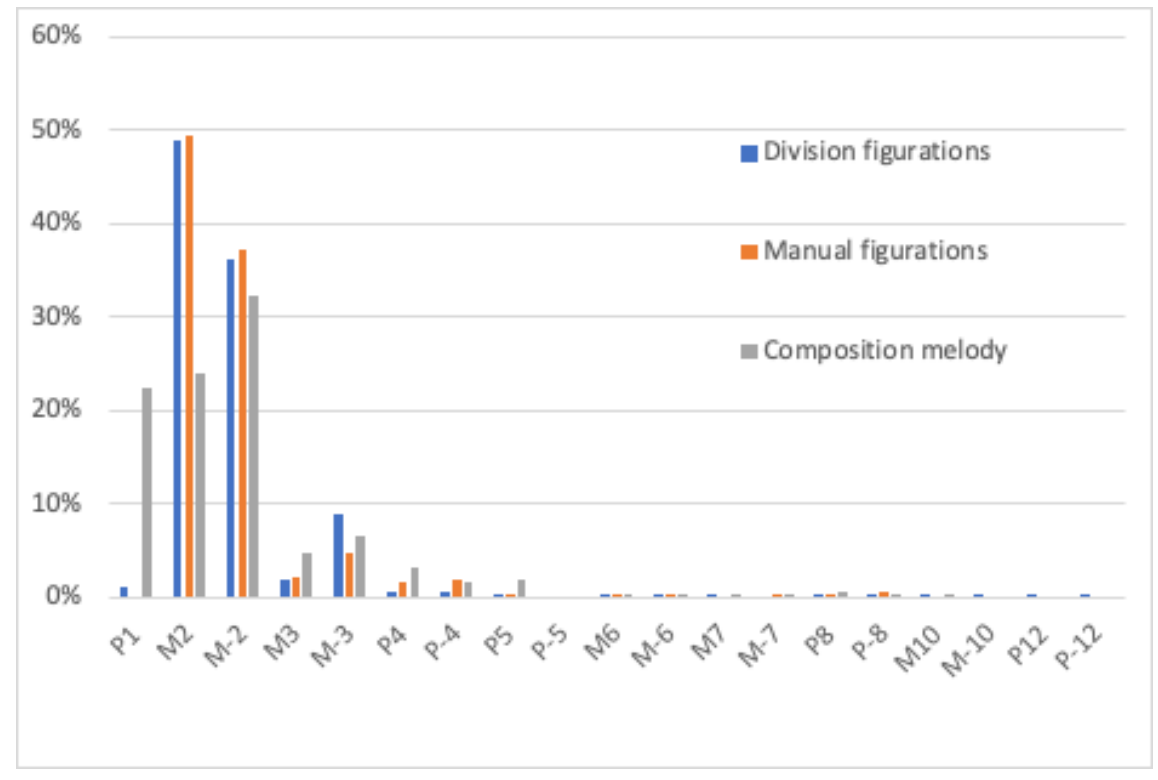

Figure 12. The relative frequency of diatonic melodic intervals in the division figurations, manual figurations and the melody of the original compositions of Bassano's corpus. 